\title{
Potential impact of sea surface temperature on rainfall over the western Philippines
}

\author{
Julie Mae B. Dado ${ }^{1 *}$ (D) and Hiroshi G. Takahashi, ${ }^{1,2}$
}

\begin{abstract}
The study used a 5 km-resolution regional climate model, the Advanced Research Weather Research and Forecasting Model, to quantify the potential impact of sea surface temperature (SST) west of the Philippines on summer monsoon rainfall on the northwestern coast of the country. A set of control simulations $(C T L)$ driven by ERA-Interim reanalysis data and the monthly National Oceanic and Atmospheric Administration Optimum Interpolation SST dataset was performed for the months of June to August of 1982-2012. A second set of simulations driven by climatological SST values was performed for the same period. The difference between these two simulation sets is analyzed to determine the sensitivity of rainfall to interannual variations in local SST, not remote SST, via a regional climate model. The CTL simulations represented spatial and temporal variations in rainfall well, yielding realistic climatological rainfall values with high spatial correlations with observations. The interannual correlation of monthly rainfall over the northwestern region of the Philippines was also high when compared to observations. The results showed that positive SST anomalies west of the Philippines induced positive rainfall anomalies in the northwestern Philippines via an increase in latent heat flux from the sea surface, implying that summer monsoon rainfall in the northwestern Philippines is modulated by interannual variations in SST west of the Philippines. The impact of SST on latent heat flux and rainfall were 20-40\%, greatly exceeding the 7\% approximation from the Clausius-Clapeyron equation, which can be explained by the enhancement of low-level winds and a weak warming of surface air temperature over the ocean.
\end{abstract}

Keywords: Summer monsoon, Rainfall, Sea surface temperature, Regional climate model

\section{Introduction}

The Philippines is located in an area primarily affected by the Asian summer monsoon. Specifically, the northwestern side of the country is affected by this system, which is known locally as the southwest monsoon (SWM). The SWM is part of the western North Pacific Monsoon within the Asian-Pacific summer monsoon system (Wang and LinHo 2002). The subsystems within the Asian summer monsoon are known to interact with each other. The monsoon onset of regions to the west of the Philippines, specifically Indochina Peninsula and South China Sea (SCS), is associated with the development in the circulation and convective features in the tropical East Indian Ocean (Ding and Chan 2005). The Asian monsoon is a complex system, but the past decade have seen significant advances in understanding climate

\footnotetext{
* Correspondence: dado-juliemaeborejon@ed.tmu.ac.jp; jbdado@gmail.com 1Department of Geography, Tokyo Metropolitan University, Minami-Osawa 1-1, Hachioji, Tokyo 192-0397, Japan

Full list of author information is available at the end of the article
}

over the region through the Monsoon Asian HydroAtmosphere Scientific Research and Prediction Initiative (MAHASRI) project (Matsumoto et al. 2016).

Rainfall is an important characteristic of the SWM season because these winds carry warm, moist air, which has a higher potential for convective activity. The northwestern regions of the Philippines experience a rainy season during June to September. A significant percentage (43\%) of the mean annual rainfall in the Philippines is associated with the SWM season, which is essential for supplying water for agriculture, energy, and domestic use (Asuncion and Jose 1980; Cayanan et al. 2011). Although there has been a general decline in the SWM mean rainfall over northwestern Philippines (Cruz et al. 2013), intense rainfall episodes still occur during the SWM season, which can result in heavy flooding.

The oceans surrounding the Philippines have a major impact on its regional climate. Large-scale oceanic impacts, including El Niño-Southern Oscillation (ENSO, Lyon and Camargo 2009; Villafuerte and 
Matsumoto 2015), have been examined in many studies. However, the impact of local sea surface temperature (SST) on the country is not well understood. Thus, there is a need to examine the local SST impact on regional rainfall over the Philippines.

Studies have noted the relationship between SST and atmosphere through the exchange of surface fluxes (Deser et al. 2010). The amount of near-surface moisture for convective rainfall is sensitive to SST through the Clausius-Clapeyron relationship and is strongly associated on interannual timescales over oceanic regions (Wentz and Schabel 2000). In general, higher SSTs correspond to increases in precipitation (Vecchi and Harrison 2002; Trenberth and Shea 2005). In addition, a recent study showed that precipitation tends to increase linearly with increasing SST over tropical monsoon basins, suggesting a noticeable impact of SST on tropical precipitation (Roxy 2014).

In the western North Pacific (WNP) region, the correlation between local rainfall and SST in the boreal summer is negative indicating that atmospheric dynamics are more dominant than ocean conditions in determining the rainfall variability of this region (Trenberth and Shea 2005; Wang et al. 2005). This relationship may be explained by the monsoon activity during this season. The summer monsoon drives rainfall but it also leads to SST cooling, hence the negative correlation between local rainfall and SST. Moreover, Trenberth and Shea (2005) also showed the covariability between surface temperature and precipitation, and although relationship is negative in WNP, it would be interesting to isolate the SST effect alone. Note that impact of local SST on rainfall variation in this region has not been evaluated yet, although these previous studies have indicated that SST cannot be the main driver of rainfall in this region.

However, it is difficult to quantify the impact of SST on rainfall from observational datasets because of strong airsea interactions (Peralta and Narisma 2014). This is similar to a mid-latitude winter monsoon case over the Sea of Japan (Takahashi and Idenaga 2013; Takahashi et al. 2013), although the range in surface air temperature is quite different. Higher SSTs bring higher latent heat fluxes under the same atmospheric conditions due to higher water vapor pressures on the sea surface, which is explained by the Clausius-Clapeyron equation. At the same time, the evaporation over the sea surface decreases the SST. In SWM condition, the strong monsoon westerly also increases latent heat flux which brings abundant rainfall to the northwestern Philippines. And since rainfall on the northwestern Philippines is predominantly controlled by the SWM airflow, the SST effect is seemingly hidden in all these dynamics. These dynamics are highly coupled, and while it is difficult to isolate the one-way impacts from observational data alone, numerical experiments are useful for understanding and quantifying such one-way impacts.

The SWM months also coincide with high tropical cyclone (TC) activity in the WNP basin including the Philippines (Cinco et al. 2016; Lyon and Camargo 2009; Takahashi and Yasunari 2006). This high frequency of TC makes a substantial contribution on rainfall over the monsoon trough (Takahashi et al. 2015a), especially in the northern island of Luzon (Cinco et al. 2016). It has also been shown that SWM rainfall is enhanced in the presence of TCs (Cayanan et al. 2011; Kubota and Wang 2009), and as such, this study also attempts to isolate the TC effect in the analysis of SWM rainfall.

To determine the contribution of SST to rainfall in a statistically robust manner, long-term or multiple-case experiments are required, as the atmospheric response to SST anomalies can vary under different atmospheric conditions (Peng et al. 1997). Moreover, long-term climate simulations can be used to investigate the extent to which interannual variations in SST affect regional climate.

In this study, we examined the response of rainfall associated with the SWM from SST forcing located west of the Philippines. We attempted to isolate the impact of SST alone, neglecting feedback from the atmosphere to the ocean, by applying SST as the boundary condition in a regional climate model. We focused on the effects of SST located west of the Philippines, as SWM winds pass through this area before arriving on the northwestern coast of the country. The SST-rainfall relationship is important in further understanding the hydroclimate within this region which translates in its significance in economic sectors such as agriculture. The methodology is discussed in detail in the "Methods/Experimental" section, and an evaluation of the performance of the model and quantification of the SST impact is described in the "Results" section. Changes in latent heating and the lack of a tropical cyclone (TC) effect are discussed in the "Discussion" section, and a summary is presented in the "Conclusions" section.

\section{Methods/Experimental \\ Model and experimental setup}

We used a non-hydrostatic regional climate model, the Advanced Research Weather Research and Forecasting Model (WRF) ver. 3.6.1 with the Advanced Research WRF dynamical core (Skamarock et al. 2008) to examine the impact of SST on precipitation. The initial and lateral boundary conditions used were from the ERAInterim reanalysis data (Berrisford et al. 2009) of the European Centre for Medium-Range Weather Forecasts, and SST data were from the Optimum Interpolation Sea Surface Temperature (OISST) ver. 2 (Reynolds et al. 2002). A set of control simulations (CTL) was performed for the months of June to August for the years 1982- 
2012. Temporally interpolated monthly values of SST were prescribed every $6 \mathrm{~h}$. Multi-year simulations were performed to investigate the robustness of the atmospheric response to SST forcing under various atmospheric conditions.

The simulation period was from May 27 to September 1 of each year. The first 5 days served as the simulation warm-up time and were not included in the analysis. The horizontal grid resolution of the first domain was $25 \mathrm{~km}$, while that of the two-way nested domain was $5 \mathrm{~km}$. Both domains had 33 terrain-following levels. Figure 1 shows the model domains. The cumulus convective parameterization (CCP) scheme was not applied to the two domains in this study because a series of test simulations with CCP yielded unrealistic amounts of rainfall. Previous studies have shown that WRF is able to capture rainfall in Asian monsoon regions without convective parameterization (Sugimoto and Takahashi 2017; Sugimoto and Takahashi 2016;
Takahashi et al. 2010). Three schemes were used: the WRF single-moment six-class microphysics scheme (Hong and Lim 2006), the Mellor-Yamada-Janjić planetary boundary layer scheme (Janjić 1994), and the unified Noah land surface model (Tewari et al. 2004). High-resolution model can represent topography and land-sea contrast in detail; thus, analysis of the SST impact was carried out using the $5 \mathrm{~km}$ model results.

\section{Sensitivity experiments}

To analyze the effect of interannual variations in SST, we performed a set of sensitivity experiments. In this experiment, the 31-year mean monthly climatological SST was computed using OISST, and then applied to the same 31-year time period as the CTL simulations (hereinafter referred to as the CLM runs). The numerical designs of the CTL and CLM runs were the same, except for application of the SST. The

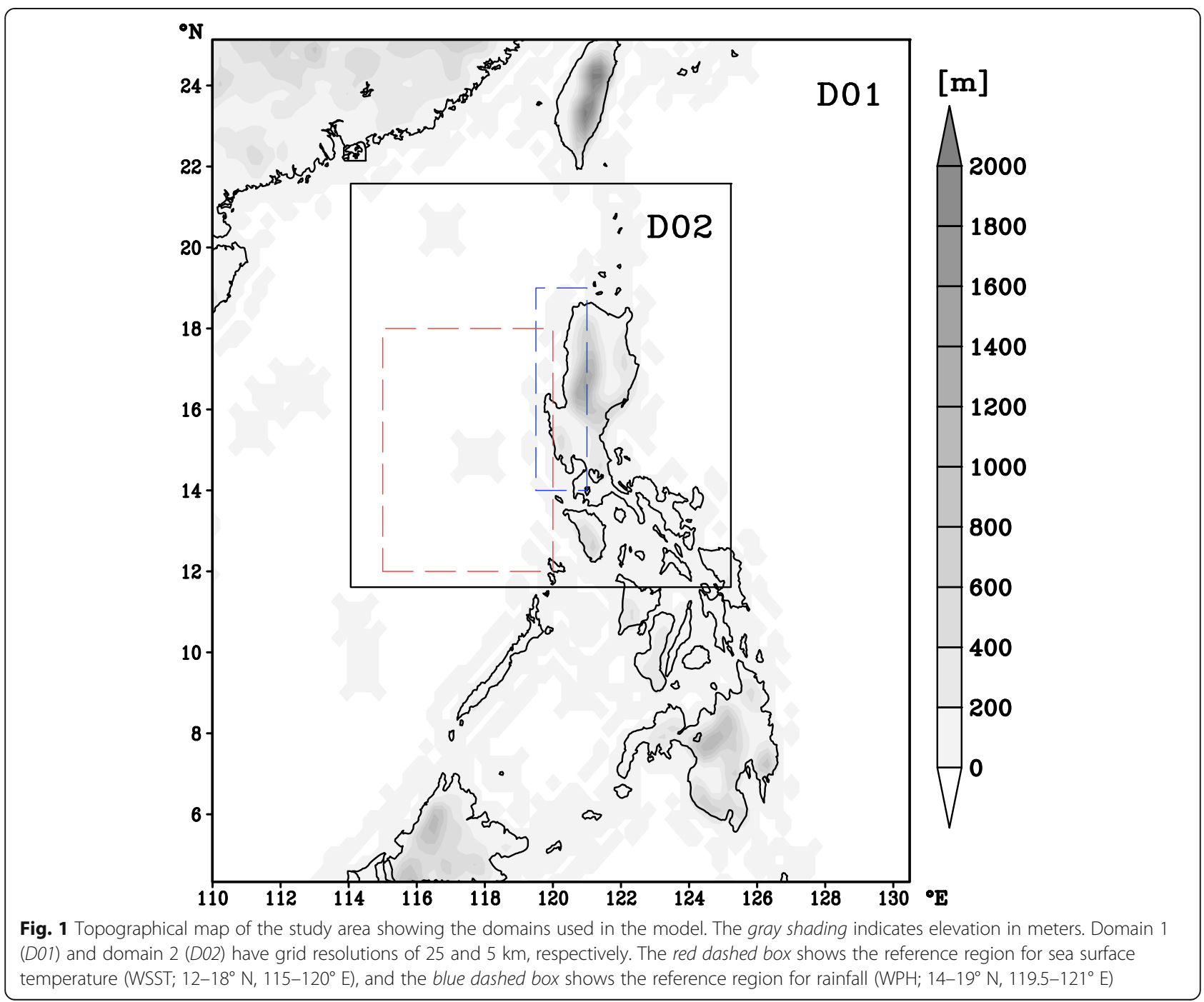


difference between the CTL and CLM runs represented the atmospheric response to the interannual SST variability. This experimental design was based on a previous study to detect local SST impact (Takahashi et al. 2015b). The local SST impact can be isolated using this design with the remote SST effect already included in the large-scale atmospheric conditions used as lateral boundary forcing for both the CTL and CLM experiments.

\section{Observational datasets used for the evaluation}

The simulated rainfall from the CTL runs was evaluated using data from the Asian Precipitation Highly-Resolved Observational Data Integration Towards Evaluation (APHRODITE) of Water Resources (Yatagai et al. 2012) and the Global Precipitation Climatology Project (GPCP) ver. 2.2 (Adler et al. 2003), and the low-level circulations were compared with data from the Japanese 55-year Reanalysis (JRA55; Kobayashi et al. 2015), which differed from the driving atmospheric datasets used in the simulations. Figure 1 shows the regions selected for a targeted analysis of the effect of SST on the climate of the northwestern Philippines. The red dashed box shows the reference region for SST (hereinafter referred as
WSST; $12-18^{\circ} \mathrm{N}, 115-120^{\circ} \mathrm{E}$ ), and the blue dashed box shows the reference region for rainfall (hereinafter referred as the northwestern region of the Philippines (WPH); $14-19^{\circ} \mathrm{N}, 119.5-121^{\circ} \mathrm{E}$ ).

\section{Tropical cyclone (TC) track data}

The number of unique TCs crossing the first domain of the simulation (D01) in Fig. 1 is counted for the months of June-August of 1982-2012 based on the best track data from the Joint Typhoon Warning Center (JTWC). For each month, years with TC counts below the mean were considered as low-TC years, which we assumed to be more representative of the SWM climate. The SST impact under this low-TC condition is explained in detail in the "Discussion" section.

\section{Results}

\section{Evaluation of CTL simulations}

First, we evaluated the performance of the simulated regional climate over the northwestern Philippines. The simulated $850 \mathrm{hPa}$ horizontal winds in domain 2 were compared with JRA55, which differed from the ERA-Interim boundary forcing data. The low-level monsoon southwesterlies were

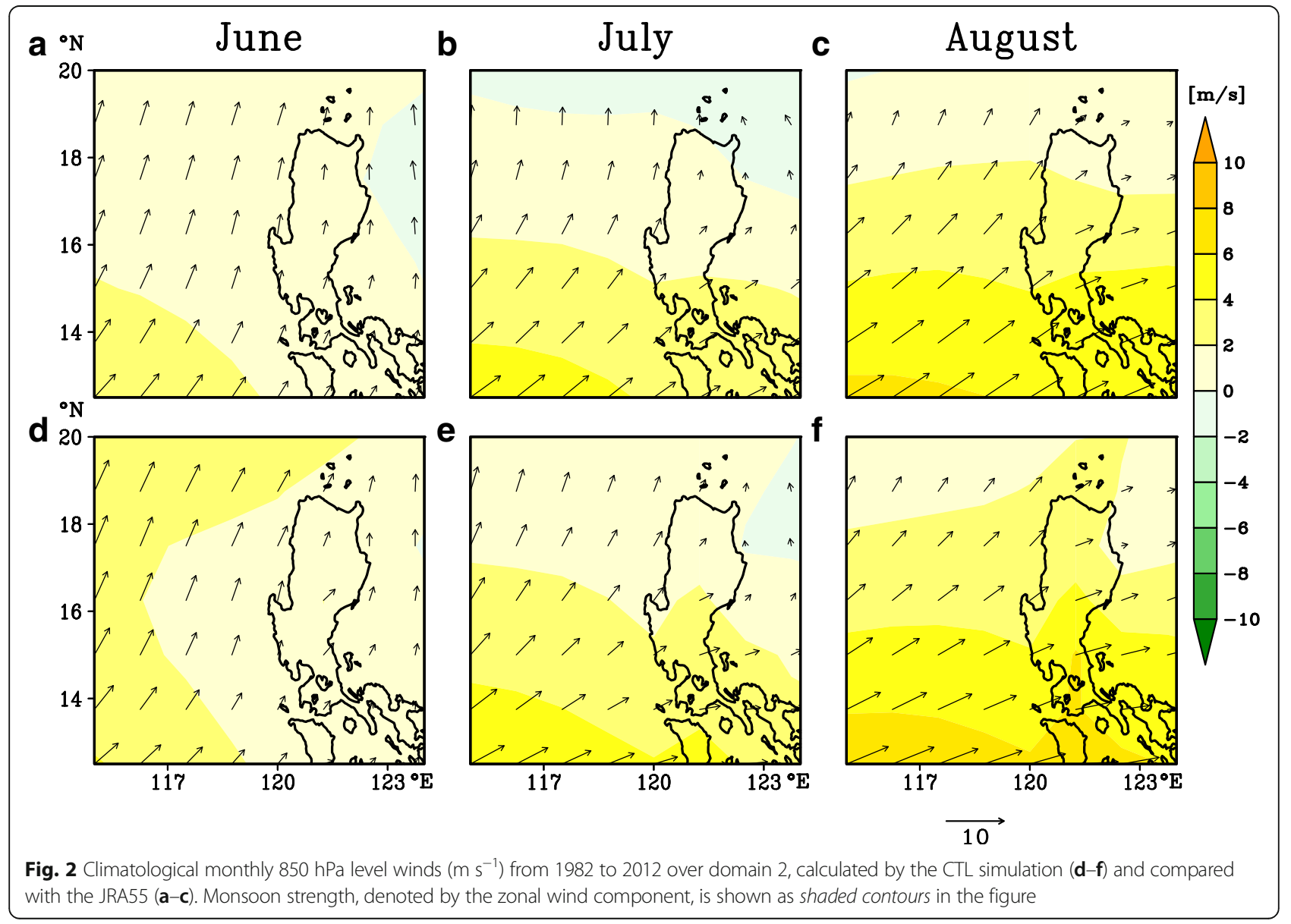


well simulated for the months of June, July, and August (Fig. 2). Furthermore, the model captured the monsoon strength, denoted by the zonal wind component.

The spatial pattern of the simulated rainfall in the CTL experiment was evaluated by comparing the climatological monthly total for each month with the APHRODITE dataset (Fig. 3). APHRODITE has data for 1950-2007; however, we only considered the years $1982-2007$ to remain consistent in reproducing climatological values for both simulations and observations. We verified that the results were nearly the same when using climatological rainfall values for 1982-2012. To facilitate the comparison between the observations and simulations, the simulated rainfall over the ocean was masked because the APHRODITE dataset was limited to the terrestrial region.

The spatial distribution of climatological rainfall was represented well by the CTL. It was able to show the west-east gradient in rainfall in the assessed months. In addition, the spatial distribution of higher rainfall values in the northwestern portion was noted in both the observational and simulated data. However, peaks in rainfall differed slightly, and the model produced higher rainfall values, predominantly in areas with high elevations. This may represent a positive bias of the simulated rainfall over high-elevation regions. In addition, the APHRODITE data were mostly obtained from coastal observation stations which can result in its underestimation of rainfall in high-elevated regions. In addition, we validated the climatological simulated rainfall against the GPCP data, which were produced from different observations, and noted a spatial distribution similar to that for APHRODITE (not shown).

The CTL monthly rainfall values in the northwestern Philippines (WPH in Fig. 1) were compared with APHRODITE monthly rainfall values for 1982-2007. Similarly, the GPCP monthly mean rainfall was obtained for the same WPH region for the years 1982-2012. Ocean grid points in the WPH region were included when comparing the CTL rainfall with the GPCP rainfall. The seasonal variation in the climatological monthly rainfall was simulated well by the model when compared with APHRODITE and GPCP data, and the WRF rainfall showed a similar seasonal peak in August (not shown).

Furthermore, we analyzed the interannual rainfall variations in the region west of the Philippines (WPH in Fig. 1) for both the observational and simulated data as scatter plots of the observed and simulated monthly precipitation for the WPH region (Fig. 4). The comparison revealed a high correlation between the monthly total

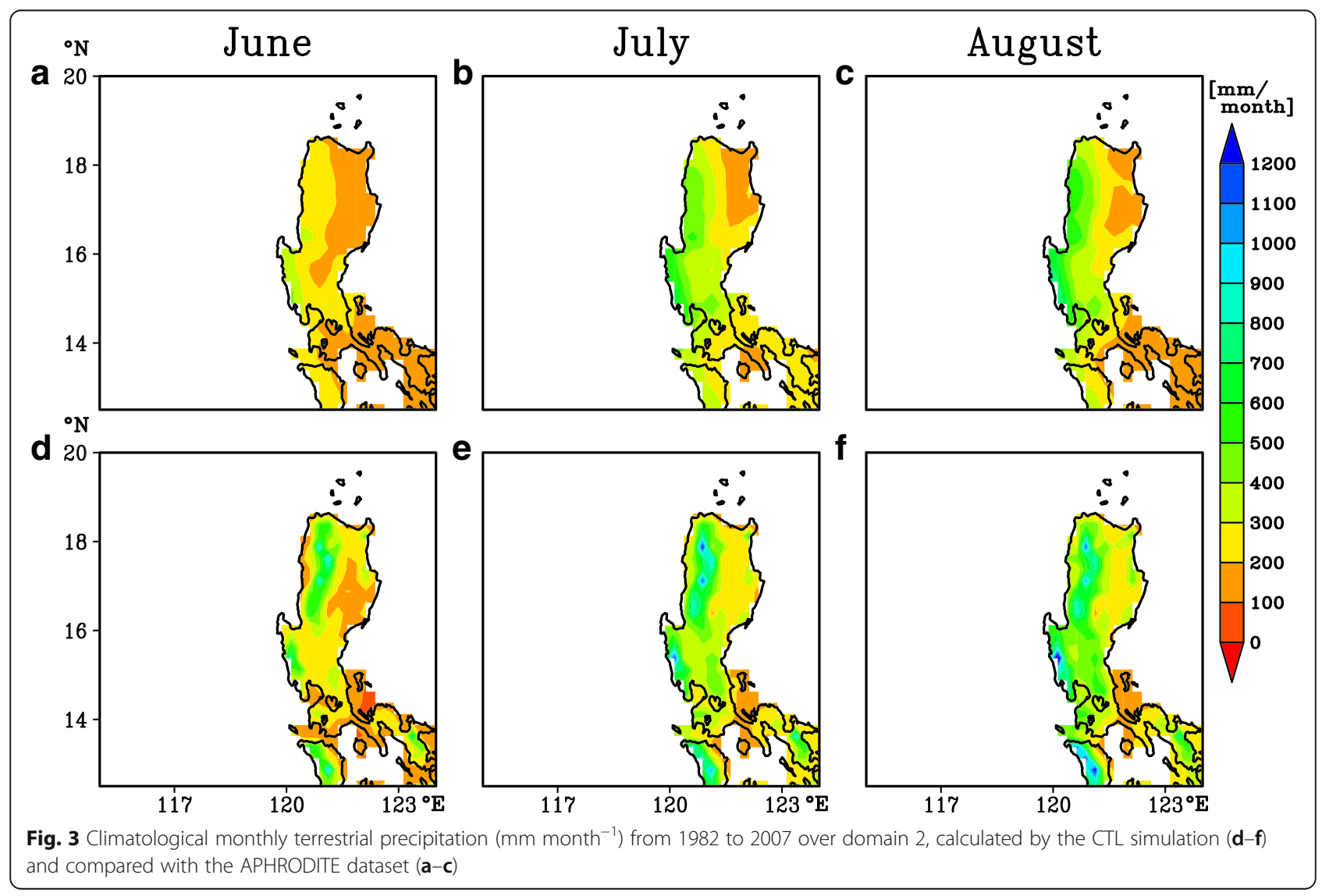



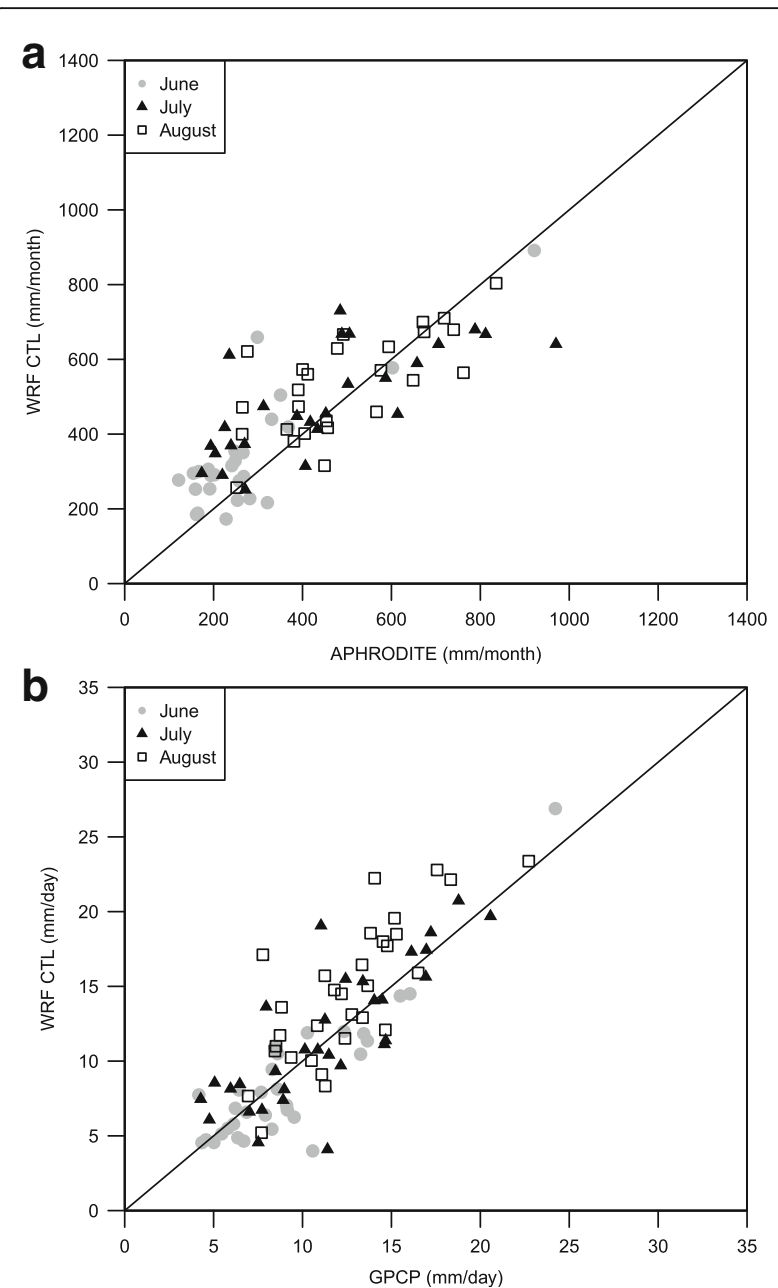

Fig. 4 a Scatter plot of the monthly total rainfall $\left(\mathrm{mm} \mathrm{month}{ }^{-1}\right)$ from the CTL simulations compared with APHRODITE data for 1982-2007. b Scatter plot of monthly mean of daily rainfall $\left(\mathrm{mm}\right.$ day $^{-1}$ ) from the $\mathrm{CTL}$ simulations compared with GPCP data for 1982-2012

rainfall from APHRODITE and the CTL simulation for the years 1982-2007 for the WPH region (Fig. 4a). The interannual seasonal mean (June to August) correlation coefficient was 0.69 . In addition, the comparison revealed a high correlation between the monthly means of daily rainfall from the GPCP data and the CTL simulation (Fig. 4b) for the WPH region, with an interannual correlation of the seasonal mean of 0.80 . These interannual correlations were statistically significant at a $99.9 \%$ confidence limit, determined using Student's $t$ test.

These results indicate that the CTL runs captured the summer rainfall in the WPH region well. Despite differences in the amount of monthly rainfall, the WRF CTL runs were able to capture the interannual and seasonal variations in precipitation in the WPH region; for the purpose of this study, the model demonstrated acceptable performance.

\section{Sensitivity of rainfall to SST variability}

To estimate the local impact of SST on rainfall spatially, we generated regression maps using Theil-Sen method to show the interannual variation in the sensitivity of monthly rainfall with area-averaged SST anomalies in the WSST region for the months of June, July, and August (Fig. 5). The sensitivity of rainfall to SST was defined as the difference between the CTL and CLM experiments. The regression coefficient was calculated using the sensitivity of the meteorological variables and the area-averaged SST anomalies. Because we used the same atmospheric boundary conditions for the CTL and CLM experiments, we could not extract the impact of remote SST. Therefore, we only evaluated the impact of SST within the model domain. The simulated results were transformed into coarser values at each 1-degree grid point from the original $5 \mathrm{~km}$ output to minimize noise. Similarly, the SST anomaly was defined as the difference between the CTL and CLM values averaged over the WSST region (Fig. 1).

Positive rainfall sensitivity to $1 \mathrm{~K} \mathrm{SST}$ warming was noted over the whole calculation domain (Fig. 5), which can be explained by the increase in latent heat flux due to the increase in SST. A detailed description of the process underlying rainfall sensitivity to changes in SST is given in the "Discussion" section. Higher and statistically significant sensitivity was observed for oceanic rainfall near the WSST region. Statistically significant values were noted in the WPH region, and August had the highest regression coefficient (Fig. 5).

These maps show that monthly rainfall in the WPH increased by $\sim 100 \mathrm{~mm} \mathrm{~K}^{-1}$ SST warming in the WSST. Because the interannual standard deviation of SST over the WSST was between 0.4 and $0.6 \mathrm{~K}, 40-60 \mathrm{~mm}$ of interannual variation in monthly rainfall could be attributed to the interannual variation of SST over the WSST (Fig. 5). Because the average climatological rainfall was $\sim 500 \mathrm{~mm}$ per month in this region, the contribution of SST to interannual rainfall variation was not negligible.

To understand the interannual relationship between SST and rainfall over and around the Philippines, we examined the time series of the SST anomaly over the WSST region and rainfall sensitivity (CTL - CLM) over the WPH region for June, July, and August (Fig. 6). A positive or negative SST anomaly generally corresponded to positive or negative rainfall sensitivity, respectively. This relationship is evident in the scatter plots (Fig. 6d-f), which clearly show that the sensitivity of rainfall in the WPH region increased with SST in the WSST region. Because the relationship is almost linear, the impact of SST on rainfall can be quantified on an interannual timescale.

Using the Theil-Sen slope estimator method, the calculated regression coefficient of rainfall in the WPH region on the area-averaged SST over the WSST region increased 

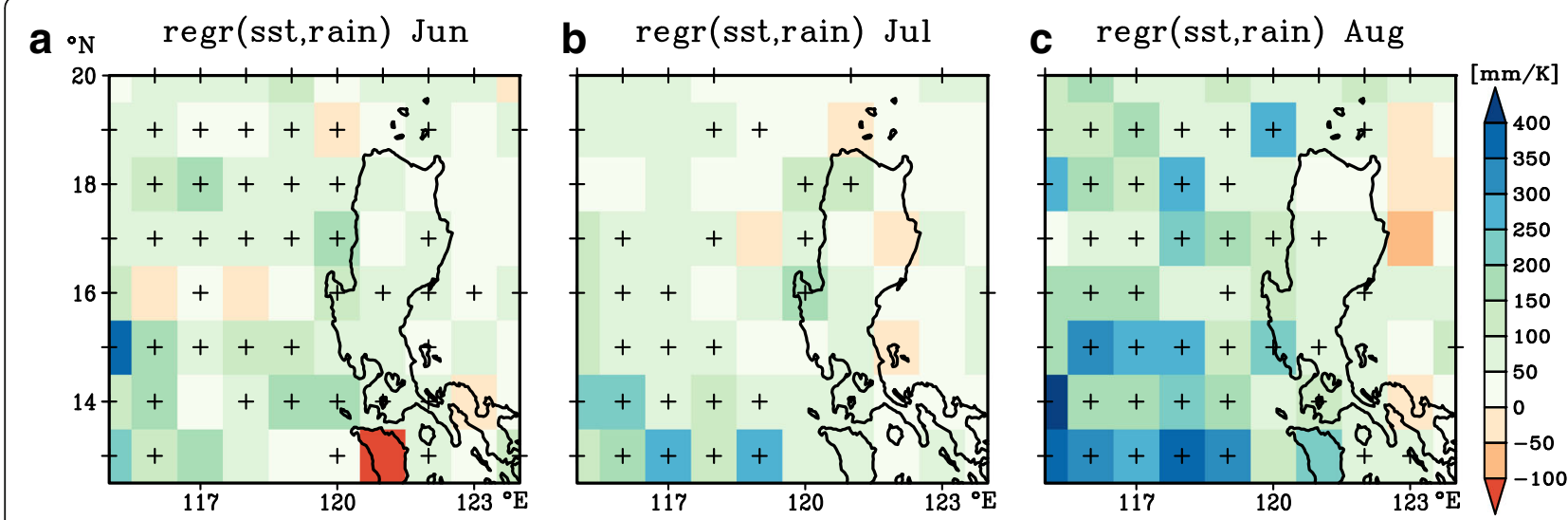

Fig. 5 Spatial map of the regression coefficients $\left(\mathrm{mm} \mathrm{K}^{-1}\right)$ of the sensitivity of monthly rainfall to the monthly SST anomaly of the WSST reference region for 1982-2012 for the months of a June, b July, and c August. Significant values at the $90 \%$ significance level are marked with plus signs, as determined by the correlation coefficients based on 29 degrees of freedom. The rainfall anomalies were remapped to a $1^{\circ}$ grid resolution

by $80.65,78.86$, and $99.69 \mathrm{~mm} \mathrm{~K}^{-1} \mathrm{SST}$ warming in the WSST region for the months of June, July, and August, respectively. This accounted for $23-37 \%$ of the climatological monthly rainfall in the WPH region, depending on the month considered. These results indicate that it is important to account for the impact of SST on rainfall in the WPH region. The mechanism behind this relationship is discussed in the following section.

\section{Discussion}

Quantification of the sensitivity of latent heat flux to SST The major sources of water vapor for rainfall in the WPH region are the evaporation from the western seas of the Philippines, which is windward of the Philippines in the summer, and water vapor transport due to the monsoon southwesterlies, especially during the SWM season. In our experiment, water vapor transport from the lateral boundary (see the western lateral boundary of Fig. 1) should have been the same, because the same lateral boundary conditions were used. Therefore, any changes in water vapor should be explained by changes in the evaporation, which is directly related to latent heat flux, within the calculation domains.

Similarly, we regressed the interannual latent heat flux sensitivity to area-averaged SST anomaly in the WSST

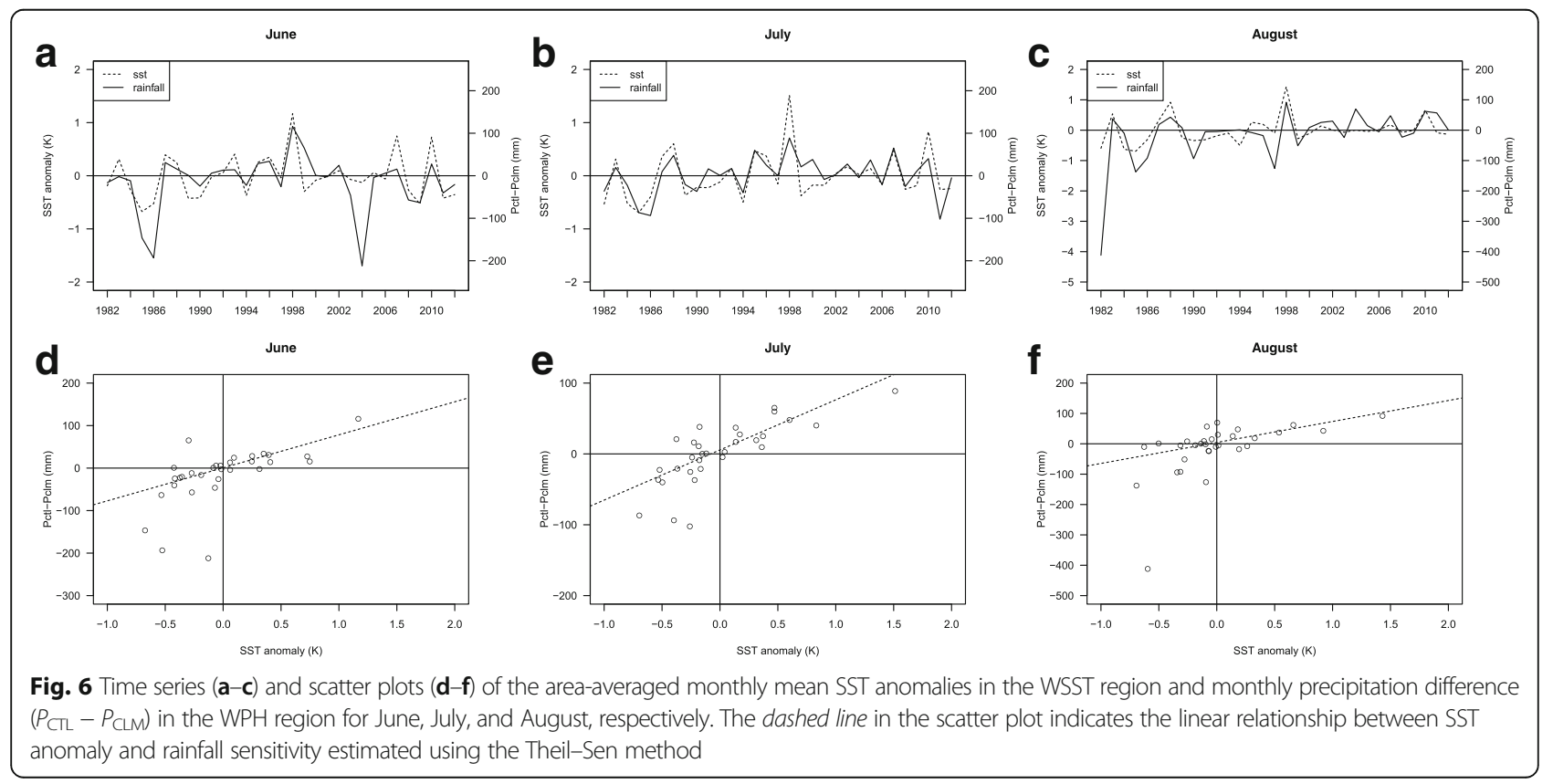




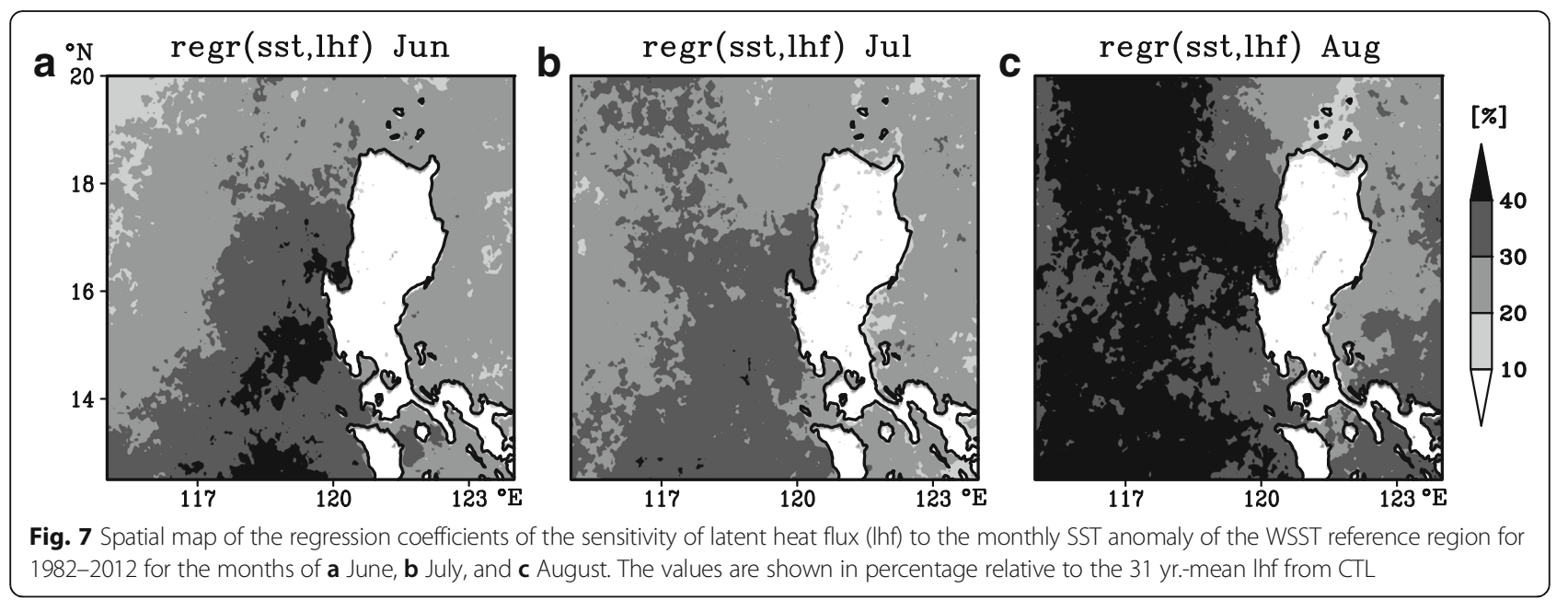

region for the months of June, July, and August. The values are expressed in percentage relative to the 31year mean latent heat from CTL experiment.

The latent heat flux increased by $20-40 \%$ per $1 \mathrm{~K} \mathrm{SST}$ warming in the WPH region, with larger increases in the seas west of the Philippines (Fig. 7). This increase in the latent heat flux was higher than the simulated change in rainfall in the WPH region. Because the relative humidity change at $2 \mathrm{~m}$ height was very small (within $-2-2 \%$ ) in most of the domain (Fig. 8), we can infer that the increase in water vapor due to the increase in latent heat was mostly converted into rainfall.

To analyze this large increase in latent heat in the domain, the bulk formula for the latent heat flux from the sea into the atmosphere can be given as.

$l E=l \rho \beta C_{H} U\left(q_{\mathrm{sat}}\left(T_{s}\right)-q\right)$,

where $l$ is the latent heat of vaporization, $E$ is the amount of evaporation, $\rho$ is the density of air, $\beta$ is the efficiency of evaporation which is 1 over water, $C_{H}$ is a mixing constant,
$U$ is the wind velocity, and $T_{s}$ is the SST over the western seas of the Philippines. $q_{\text {sat }}$ is the saturated specific humidity at $T_{s}$, and $q$ is the specific humidity of the lower atmosphere. Therefore, latent heating can be explained by wind velocity and the difference between the saturated specific humidity at SST and the surface specific humidity.

Changes in wind speed and specific humidity are likely critical in explaining the much larger sensitivities in latent heat flux over the WSST regions than expected from the Clausius-Clapeyron equation. The changes in the wind speed per $1 \mathrm{~K} \mathrm{SST}$ warming were mostly positive (within 10\%), which increased the latent heat flux over the WSST region by $5-10 \%$ percent (Fig. 9). This increase in wind speed was associated with a downward transport of momentum due to the development of the planetary boundary layer height (e.g., Stull 2006) and enhancement of regional circulation that is accompanied by latent heating and convective activity. The $2 \mathrm{~m}$ air temperature increase was $<1 \mathrm{~K}$ across most of the

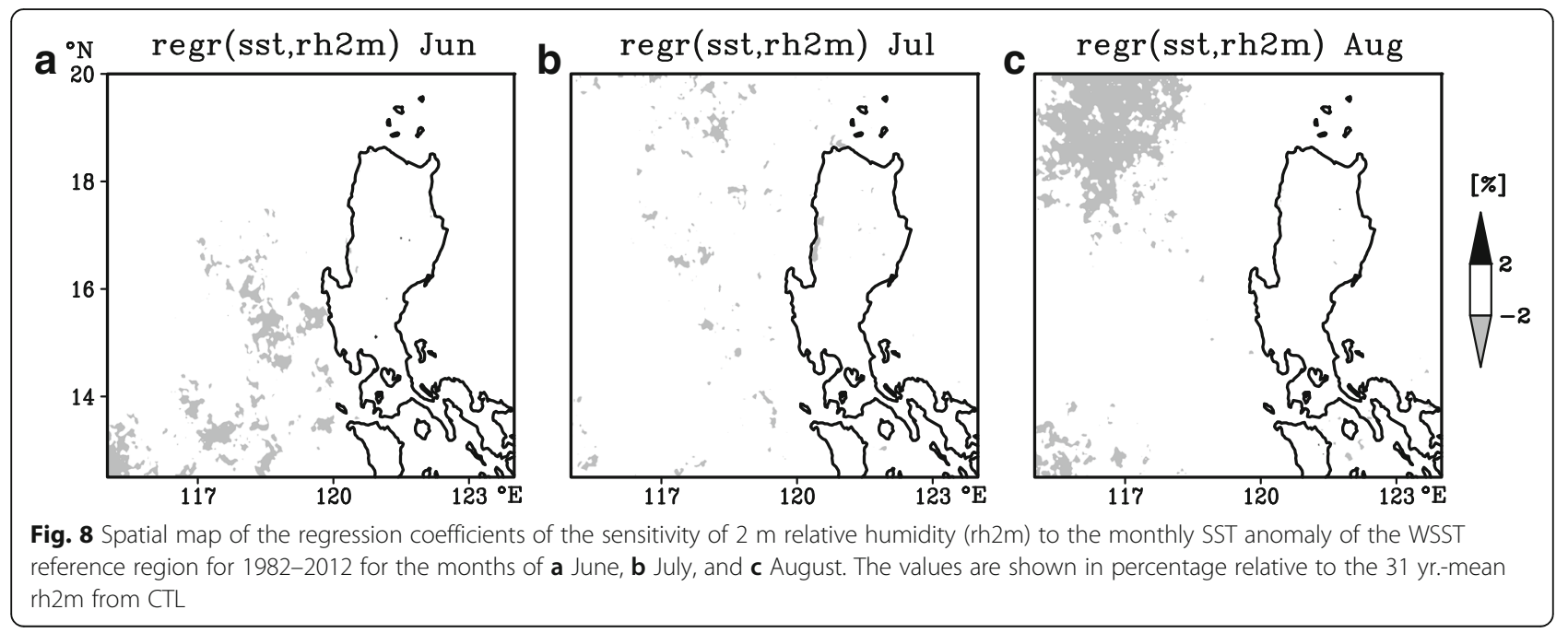




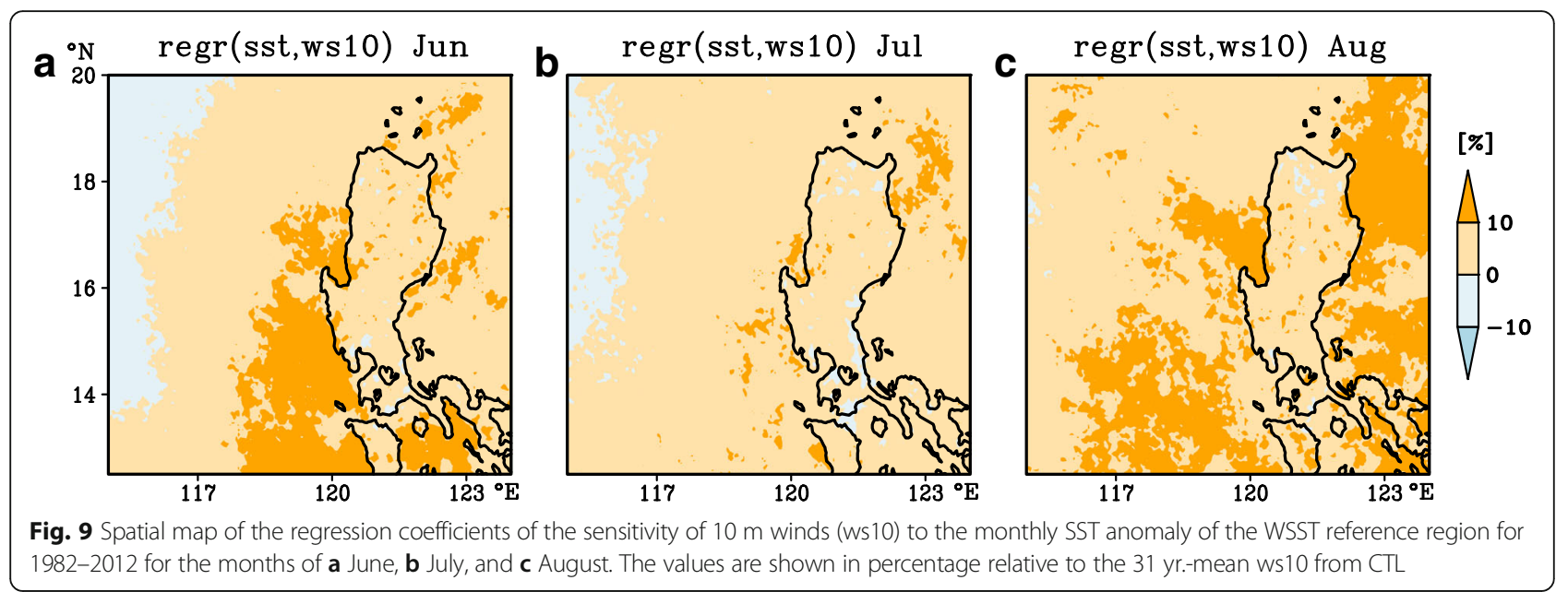

domain (Fig. 10). Due to the small change in relative humidity, the rate of regressed sensitivity in $q$ between the CTL and CLM simulations onto the area-averaged SST warming was expected to be $<7 \%$, which is the theoretical value in an idealized situation under the Clausius-Clapeyron equation. Based on this, the change in the term $\left(q_{\text {sat }}\left(T_{s}\right)-q\right)$ has a larger value than $7 \%$. The small sensitivity in the $2 \mathrm{~m}$ air temperature can contribute to the positive sensitivity in latent heat flux by a few percent. Moreover, the changes in relative humidity were small, but mostly exhibited negative sensitivity to SST warming over the WSST region, which can also contribute $1-2 \%$ to the large increase in latent heat flux.

There are additional possible effects that can increase latent heat flux or rainfall. Takahashi et al. (2013) suggested that an increase in the height of the planetary boundary layer could contribute to the increase in latent heat flux. In addition, an increase in precipitable water of $<7 \%$ in the Clausius-Clapeyron equation suggested that the increased water vapor due to the increase of latent heat flux was excessively used for rainfall, decreasing the precipitable water over the domain.

Table 1 summarizes the changes in the atmospheric variables due to $1 \mathrm{~K} \mathrm{SST}$ warming in the WSST region. These results suggest that the large changes in the latent heating can be explained mainly by the increase in surface wind speeds coupled with weak air temperature warming near the surface.

\section{Isolating the effect of tropical cyclones}

The western North Pacific basin is highly active for TCs and many TCs pass near or through the Philippines, especially during the months of July and August in the SWM season (Cinco et al. 2016); therefore, this subsection discusses the effects of TCs on the sensitivity to local SST changes. We examined whether there was a systematic difference in sensitivity between years of high and low TC activity, so as to only include years representative of a SWM effect.

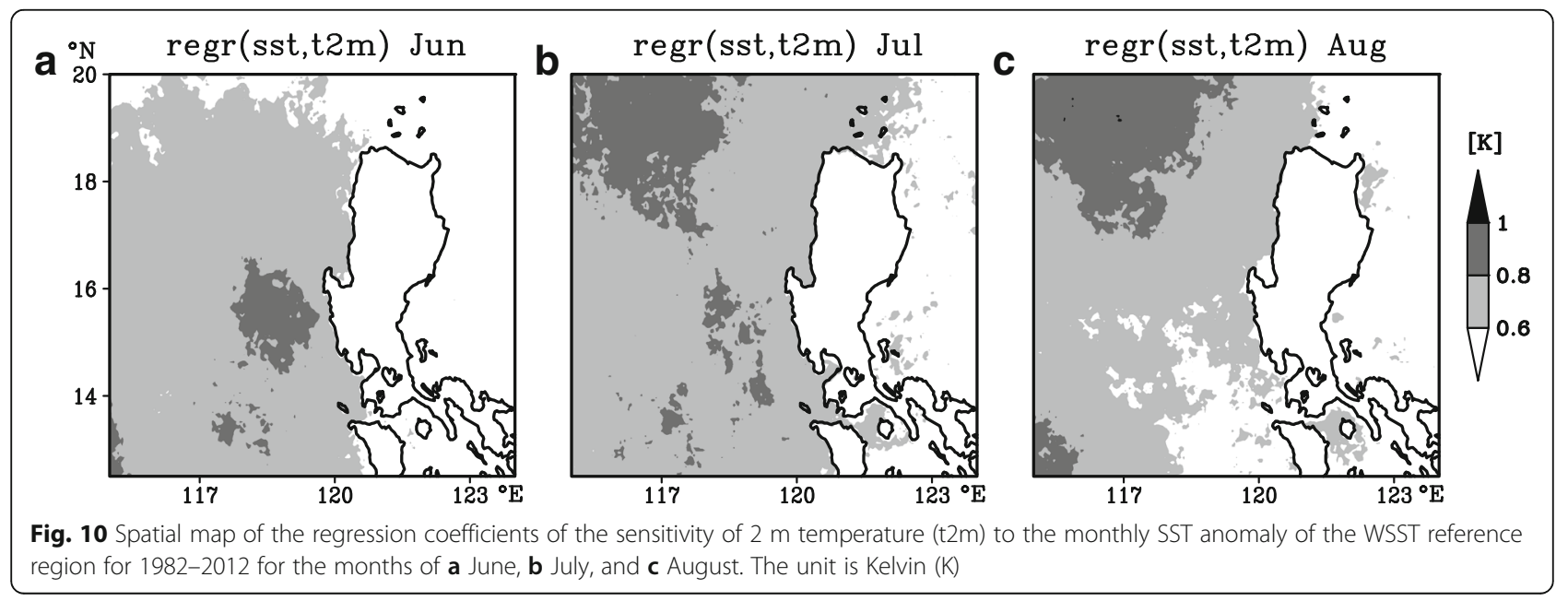


Table 1 Change in atmospheric variables due to a 1 K SST warming in the WSST region from 1982 to 2012. The actual values are shown with the percentage change relative to the mean CTL value (in parentheses). All variables were obtained from an average of the WSST region, except for rainfall, which was from the WPH region

\begin{tabular}{llll}
\hline & June & July & August \\
\hline Rainfall $(\mathrm{mm})$ & $80.65(37.95 \%)$ & $78.86(24.3 \%)$ & $99.69(23.19 \%)$ \\
Latent heat flux $\left(\mathrm{W} / \mathrm{m}^{2}\right)$ & $35.77(32.88 \%)$ & $33(30.9 \%)$ & $45.5(41.58 \%)$ \\
$2 \mathrm{~m}$ relative humidity & $-1.54(-1.74 \%)$ & $-1.44(-1.62 \%)$ & $-1.42(-1.58 \%)$ \\
$10 \mathrm{~m}$ wind speed $(\mathrm{m} / \mathrm{s})$ & $0.28(5.73 \%)$ & $0.24(4.56 \%)$ & $0.53(8.68 \%)$ \\
$2 \mathrm{~m}$ temperature $(\mathrm{K})$ & $0.73(0.24 \%)$ & $0.74(0.25 \%)$ & $0.67(0.22 \%)$ \\
Precipitable water vapor $(\mathrm{mm})$ & $2.81(5.25 \%)$ & $2.32(4.23 \%)$ & $2.65(4.75 \%)$ \\
\hline
\end{tabular}
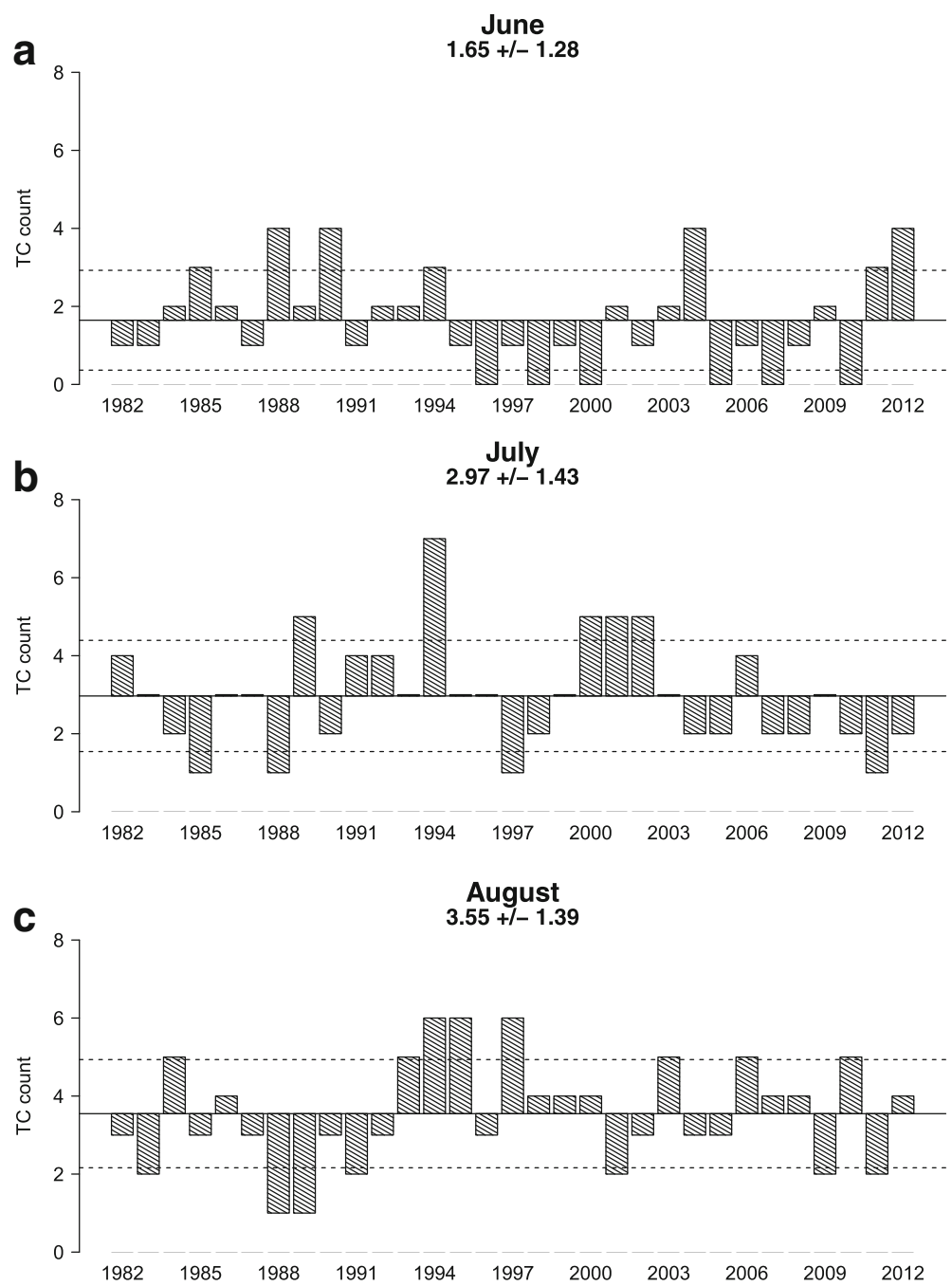

Fig. 11 Number of tropical cyclones passing through domain 1 (D01 in Fig. 1) for each month (a-c) from 1982 to 2012 based on JTWC best track data. The counts are plotted around the mean, while the dashed lines indicate the standard deviation. The means and standard deviations are written in the graph for each month 
Figure 11 shows the number of TCs entering the region bounded by D01 in Fig. 1. TC counts are based on the JTWC best track data, not on the actual TC simulated by the model. To confirm the presence of TCs in the model, we compared the $850 \mathrm{hPa}$ zonal winds from the boundary data, ERA-Interim, with WRF for years with high TC counts. The easterly wind footprints signify the presence of a TC in our model domain, and these footprints are consistent with the TC count from the JTWC data (not shown).

The mean count from 1982 to 2012 was calculated for each month, with years below the mean considered as low-TC years (Fig. 11). The relationships between the variables shown in Table 1 were recalculated for these low-TC years, which were assumed to more representative of the SWM climate (Additional file 1: Table S2).

The relationships held true in both low- and highTC years (Additional file 1: Table S2), and the results were similar to those in Table 1, wherein the large changes in latent heating were mainly attributed to enhancement of low-level winds and weak warming at the surface. Notably, the differences in the sensitivity between low- and high-TC years were not systematic, implying that the impact of TCs around the Philippines is complicated; therefore, we concluded that we cannot easily determine whether TCs intensify or weaken the SST sensitivity. Although this may be largely due to the intensity of the TCs and their corresponding locations, we were unable to determine this in our experiments because of the non-linearity of TC behavior. As previous studies have noted, the presence of a TC in the vicinity of the Philippines may enhance southwesterly winds (Cayanan et al. 2011); however, future studies should statistically analyze the interaction between SWM and TCs around the Philippines.

\section{Conclusions}

In this study, we explored the potential impact of SST west of the Philippines on summer monsoon rainfall on the northwestern coast of the country. We performed two sets of simulations using the same initial and lateral boundary conditions, but with different SST conditions, from June to August for 1982-2012.

The spatial pattern of monthly rainfall was simulated well by the CTL simulation, with a clear horizontal delineation between rainfall in the western and eastern regions of the Philippines during the summer monsoon months. The monthly rainfall values were in close agreement with the two observational datasets used.

Positive SST anomalies in the WSST region corresponded to positive rainfall anomalies in the WPH region. Based on the regression analysis, rainfall in the northwestern region of the Philippines is modulated by interannual variations in SST west of the Philippines by $80 \sim 100 \mathrm{~mm} \mathrm{~K}^{-1}$ SST warming. This translates to $20 \sim 40 \%$ of the rainfall change in the WPH region relative to climatological values in the region.

The change in rainfall exceeded the theoretical approximation of $7 \%$ due to the Clausius-Clapeyron contribution, which may be attributed to the increase in the latent heat flux in the WSST region. This latent heat flux increase is associated with an increase in surface winds coupled with a weak near-surface warming. We isolated the impact of TCs and noted that this mechanism holds true for years with low or no TC effects, which are more representative of the SWM climate.

\section{Additional file}

Additional file 1: Table S2. Change in atmospheric variables due to 1 K SST warming in the WSST region from 1982 to 2012 for high- and low-TC years. The actual values are shown with the percentage change relative to the mean $C T L$ value (in parentheses). All variables were obtained from an average for the WSST region, except for rainfall, which was from the WPH region. (DOCX $110 \mathrm{~kb}$ )

\section{Abbreviations}

APHRODITE: Asian Precipitation Highly-Resolved Observational Data Integration Towards Evaluation of Water Resources; CCP: Cumulus convective parameterization; CLM: Climatological SST-driven simulation; CTL: Monthly SST-driven simulation; ENSO: El Niño-Southern Oscillation; GPCP: Global Precipitation Climatology Project; JRA55: Japanese 55-year Reanalysis; JWC: Joint Typhoon Warning Center; Ihf: Latent heat flux; OISST: Optimum Interpolation Sea Surface Temperature; rh2m: 2 m relative humidity; SCS: South China Sea; SST: Sea surface temperature; SWM: Southwest monsoon; t2m: $2 \mathrm{~m}$ temperature; TC: Tropical cyclone; WNP: Western North Pacific; WPH: Reference region for rainfall northwest of the Philippines; WRF: Advanced Research Weather Research and Forecasting Model ver. 3.6.1; ws 10: $10 \mathrm{~m}$ wind speed; WSST: Reference region for sea surface temperature west of the Philippines

\section{Acknowledgments}

We thank Dr. Shiori Sugimoto for preparing the ERA-Interim boundary datasets used in the WRF simulations. This study is partly supported by the 8th Japan Aerospace Exploration Agency (JAXA) Precipitation Measuring Mission (PMM) Project No. 309. JM Dado is a recipient of the "Asian Human Resources Fund" scholarship from the Tokyo Metropolitan Government. We are also grateful for the constructive comments from the editor and reviewers in further improving this manuscript

\section{Funding}

JM Dado is a recipient of the "Asian Human Resources Fund" scholarship from the Tokyo Metropolitan Government. This study is also partly supported by the 8th Japan Aerospace Exploration Agency (JAXA) Precipitation Measuring Mission (PMM) Project No. 309.

\section{Authors' contributions}

$J M D$ proposed the topic and carried out the experiments in the study. JMD and HGT designed the study and analyzed the data and their interpretation. Both authors collaborated in the construction of the manuscript and both read and approved the final manuscript.

\section{Authors' information}

JMD is a former researcher at the Manila Observatory in the Philippines and is currently doing her doctoral studies at Tokyo Metropolitan University. HGT is an assistant professor at Tokyo Metropolitan University and a scientist at Japan Agency for Marine-Earth Science and Technology (JAMSTEC). 


\section{Competing interests}

The authors declare that they have no competing interest.

\section{Publisher's Note}

Springer Nature remains neutral with regard to jurisdictional claims in published maps and institutional affiliations.

\section{Author details}

'Department of Geography, Tokyo Metropolitan University, Minami-Osawa 1-1, Hachioji, Tokyo 192-0397, Japan. ${ }^{2} J a p a n$ Agency for Marine-Earth Science and Technology, 3173-25, Showa-machi, Kanazawa-ku, Yokohama, Kanagawa 236-0001, Japan

\section{Received: 31 March 2017 Accepted: 5 July 2017}

Published online: 15 August 2017

\section{References}

Adler RF, Huffman GJ, Chang A, Ferraro R, Xie P, Janowiak J, Rudolf B, Schneider U, Curtis S, Bolvin D, Gruber A, Susskind J, Arkin P, Nelkin E (2003) The version 2 Global Precipitation Climatology Project (GPCP) monthly precipitation analysis (1979-present). J Hydrometeorol 4:1147-1167

Asuncion JF, Jose AM (1980) A study of the characteristics of the northeast and southwest monsoons in the Philippines. National Research Council of the Philippines (NRCP) assisted project, p 49 (available from Philippine Atmospheric Geophysical and Astronomical Services Administration (PAGASA))

Berrisford P, Dee D, Fielding K, Fuentes M, Kallberg P, Kobayashi S, Uppala S (2009) The ERA-Interim archive. ERA report series 1, European Centre for Medium-Range Weather Forecasts

Cayanan EO, Chen T-C, Argete JC, Yen M-C, Nilo PD (2011) The effect of tropica cyclones on southwest monsoon rainfall in the Philippines. J Meteorol Soc Japan 89A:123-139. doi:10.2151/jmsj.2011-A08

Cinco TA, de Guzman RG, Ortiz AM, Delfino RJ, Lasco RD, Ares E (2016) Observed trends and impacts of tropical cyclones in the Philippines. Int J Climatol 36: 4638-4650

Cruz FT, Narisma GT, Villafuerte MQ II, Cheng Chua KU, Olaquera LM (2013) A climatological analysis of the southwest monsoon rainfall in the Philippines. Atmos Res 122:609-616. doi:10.1016/j.atmosres.2012.06.010

Deser C, Alexander MA, Xie SP, Phillips AS (2010) Sea surface temperature variability: patterns and mechanisms. Annu Rev Mar Sci 2:115-143. doi:10.1146/annurev-marine-120408-151453

Ding Y, Chan JCL (2005) The east Asian summer monsoon: an overview. Meteorog Atmos Phys 89:117-142. doi:10.1007/s00703-005-0125-z

Hong SY, Lim JOJ (2006) The WRF single-moment 6-class microphysics scheme (WSM6). J Korean Meteor Soc 42:129-151

Janjić Zl (1994) The step-mountain eta coordinate model: further developments of the convection, viscous sublayer, and turbulence closure schemes. Mon Wea Rev 122:927-945

Kobayashi S, Ota Y, Harada Y, Ebita A, Moriya M, Onoda H, Onogi K, Kamahori H, Kobayashi C, Endo H, Miyaoka K, Takahashi K (2015) The JRA-55 reanalysis: general specifications and basic characteristics. J Meteorol Soc Jpn 93(1):5-48 doi:10.2151/jmsj.2015-001

Kubota H, Wang B (2009) How much do tropical cyclones affect seasonal and interannual rainfall variability over the western North Pacific? J. Clim. 22(20): 5495-5510, doi:10.1175/2009JCLI2646.1.

Lyon B, Camargo SJ (2009) The seasonally-varying influence of ENSO on rainfall and tropical cyclone activity in the Philippines. Clim Dyn 32:125-141. doi:10. 1007/s00382-008-0380-z

Matsumoto J, Oki T, Yamanaka MD, Hayashi T, Asanuma J (2016) 10 years of MAHASRI: accomplishments and the international science conference wrapup. GEWEX Newsletter 26(4):10-23

Peng S, Robinson WA, Hoerling MP (1997) The modeled atmospheric response to mid-latitude SST anomalies and its dependence on background circulation states. J Clim 10:971-987. doi:10.1175/1520-0442(1997)010<0971:TMARTM>2.0.CO;2

Peralta JA I, Narisma G (2014) The influence of West Philippine Sea surface temperatures on southwest monsoon rainfall in the Philippines. Undergraduate thesis. Philippines: Ateneo de Manila University.

Reynolds RW, Rayner NA, Smith TM, Stokes DC, Wang W (2002) An improved in situ and satellite SST analysis for climate. J Clim 15:1609-1625. doi:10.1175/ 1520-0442(2002)015<1609:AllSAS>2.0.CO;2
Roxy M (2014) Sensitivity of precipitation to sea surface temperature over the tropical summer monsoon region —and its quantification. Clim Dyn 43:1159-1169. do::10.1007/s00382-013-1881-y

Skamarock WC, Klemp JB, Dudhia J, Gill DO, Barker DM, Duda MG, Huang X-Y, Wang W, Powers JG (2008) A description of the advanced research WRF version 3. NCAR Tech. Note NCAR/TN-475+STR. 113. doi:10.5065/D68S4MVH

Stull R (2006) The atmospheric boundary layer. In: Wallace JM, Hobbs PV (ed) Atmospheric science: an introductory survey, 2nd edn. USA: Elsevier Inc.

Sugimoto S, Takahashi HG (2016) Effect of spatial resolution and cumulus parameterization on simulated precipitation over South Asia. SOLA 12A:7-12. doi:10.2151/sola.12A-002

Sugimoto S, Takahashi HG (2017) Seasonal differences in precipitation sensitivity to soil moisture in Bangladesh and surrounding regions. J Clim 30:921-938. doi:10.1175/jcli-d-15-0800.1

Takahashi HG, Idenaga T (2013) Impact of SST on precipitation and snowfall on the sea of Japan side in the winter monsoon season: timescale dependency. J Meteorol Soc Jpn 91:639-653. doi:10.2151/jmsj.2013-506

Takahashi HG, Yasunari T (2006) A climatological monsoon break in rainfall over Indochina - a singularity in the seasonal march of the Asian summer monsoon. J Clim 19:1545-1556. doi:10.1175/JCLI3724.1

Takahashi HG, Yoshikane T, Hara M, Takata K, Yasunari T (2010) High-resolution modelling of the potential impact of land surface conditions on regional climate over Indochina associated with the diurnal precipitation cycle. Int J Climatol 30:2004-2020. doi:10.1002/joc.2119

Takahashi HG, Ishizaki NN, Kawase H, Hara M, Yoshikane T, Ma X, Kimura F (2013) Potential impact of sea surface temperature on winter precipitation over the Japan Sea side of Japan: a regional climate modeling study. J Meteorol Soc Jpn 91:471-488. doi:10.2151/jmsj.2013-404

Takahashi HG, Adachi SA, Sato T, Hara M, Ma X, Kimura F (2015b) An oceanic impact of the Kuroshio on surface air temperature on the Pacific coast of Japan in summer: regional $\mathrm{H}_{2} \mathrm{O}$ greenhouse gas effect. J Clim 28:7128-7144. doi:10.1175/JCLI-D-14-00763.1

Takahashi HG, Fujinami H, Yasunari T, Matsumoto J, Baimoung S (2015a) Role of tropical cyclones along the monsoon trough in the 2011 Thai flood and interannual variability. J Clim 28:1465-1476. doi:10.1175/jcli-d-14-00147.1

Tewari M, Chen F, Wang W, Dudhia J, LeMone MA, Mitchell K, Ek M, Gayno G, Wegiel J, Cuenca R (2004) Implementation and verification of the unified NOAH land surface model in the WRF model. 20th conference on weather analysis and forecasting/16th conference on numerical weather prediction, pp. 11-15

Trenberth KE, Shea DJ (2005) Relationships between precipitation and surface temperature. Geophys Res Lett 32(L14703). doi:10.1029/2005GL022760

Vecchi GA, Harrison DE (2002) Monsoon breaks and subseasonal sea surface temperature variability in the bay of Bengal. J Clim 15:1485-1493. doi:10. 1175/1520-0442(2002)015<1485:MBASSS>2.0.CO;2

Villafuerte MQ II, Matsumoto J (2015) Significant influences of global mean temperature and ENSO on extreme rainfall in Southeast Asia. J Clim 28:1905-1919. doi:10.1175/JCLL-D-14-00531.1

Wang B, LinHo L (2002) Rainy season of the Asian-Pacific summer monsoon. J Clim 15:386-398. doi:10.1175/1520-0442(2002)015<0386:RSOTAP>2.0.CO;2

Wang B, Ding Q, Fu X, Kang I-S, Jin K, Shukla J, Doblas-Reyes F (2005) Fundamental challenge in simulation and prediction of summer monsoon rainfall. Geophys Res Lett 32:L15711. doi:10.1029/2005GL022734

Wentz F, Schabel M (2000) Precise climate monitoring using complementary satellite data sets. Nature 403:414-416. doi:10.1038/35000184

Yatagai A, Kamiguchi K, Arakawa O, Hamada A, Yasutomi N, Kitoh A (2012) APHRODITE: constructing a long-term daily gridded precipitation dataset for Asia based on a dense network of rain gauges. Bull Amer Meteor Soc 93: 1401-1415. doi:10.1175/BAMS-D-11-00122.1 